\title{
DIGITAL TEHNOLOGIES. AN OVERVIEW OF CURRENT EVOLUTIONS AND IMPACT
}

\author{
PhD Claudia Ionescu, Academy of Economic Studies of Bucharest \\ Vasile Dumitraş, Romanian Court of Accounts
}

\begin{abstract}
Various observers describe today's global economy as one in transition to a knowledge economy, as an extension of an information society. The transition requires that the rules and practices that determined success in the industrial economy need rewriting in an interconnected, globalized economy where knowledge resources such as know-how and expertise are as critical as other economic resources. According to analysts of the knowledge economy, these rules need to be rewritten at the levels of firms and industries in terms of knowledge management and at the level of public policy as knowledge policy or knowledge-related policy.

The digital and ICT revolutions are twin revolutions. Information and communications technology (ICT) refers to a broad field encompassing computers, communications equipment and the services associated with them. It includes the telephone, cellular networks, satellite communication, broadcasting media and other forms of communication.
\end{abstract}

Keywords: digital revolutions, communication equipment, broadcasting media

JEL Codes: O31, E01, O33

\section{Introduction}

One of the many challenges facing the countries today is preparing their societies and governments for globalization and the information and communication revolution. Policy-makers, business executives, academics, and ordinary citizens are increasingly concerned with the need to make their societies competitive in the emergent information economy.

Technological breakthroughs have revolutionized communications and the spread of information. By the 1940s television was broadcasting both sound and visuals to a vast public. In 1943, the world's first electronic computer was created. However, it was only with the invention of the microprocessor in the 1970s that computers became accessible to the public. In the 1990s, the Internet migrated from universities and research institutions to corporate headquarters and homes.

All of these technologies deal with information storage and transmission. However, the one characteristic of computer technology that sets it apart from earlier analog technologies is that it is digital. Analog technologies incorporate a combination of light and sound waves to get messages across, while digital technology, with its system of discontinuous data or events, creates a universal model to represent information that is expressed by almost anything using light and sound waves.

To use an analogy, a digital world is a world united by one language, a world where people from across continents share ideas with one another and work together to build projects and ideas. More voluminous and accurate information is accumulated and generated, and distributed to an audience that understands exactly what is said. This in turn allows the recipients of the information to use it for their own purposes, to create ideas and to redistribute more ideas.

The digital and ICT revolutions are twin revolutions. Information and communications technology (ICT) refers to a broad field encompassing computers, communications equipment and the services associated with them. It includes the telephone, cellular networks, satellite communication, broadcasting media and other forms of communication. 
Today, voice is translated into data packets, sent over networks to remote locations, sometimes thousands of kilometers away, and, upon receipt, translated back to voice. Even television is not immune to digitization. It is also possible to use the television to surf the Internet. The digital TV will allow people from different locations to chat with each other while watching a program. With everything becoming digital, television, voice telephony, and the Internet can use similar networks.

\section{The main characteristics of digital technology}

The main characteristics of digital technology are:

Media Integrity. Data stored in analog formats cannot be reproduced without degradation. The more copies made, the worse the copies get. Digital data, on the other hand, do not suffer such deterioration with reproduction. For instance, movies, videos, music and audio files in digital format can be copied and distributed with a quality that is as good as the original.

Media Integration. One of the major limitations of many conventional technologies is their inability to combine media types. With digital data, it is easy to combine media. Thus, phones with video, or interactive sound with pictures, become possible. Hence the term multimedia.

Flexible Interaction. The digital domain supports a great variety of interactions, including one-on-one conferences, one-to-many broadcasts, and everything in between. In addition, these interactions can be synchronous and in real time.

Transactions. The ability to combine the transactional capability of computers and computer networks with digital media is another interactive advantage of the digital domain. Placing an order and finalizing a transaction becomes as easy as filling in an electronic form and clicking a button.

Tailoring. Software developed for digital communications and interaction is designed so that users may tailor their use of the tool and the media in a manner not possible with conventional analog technologies.

Editing. The conventional alternatives for manipulating text, sound, images, and video are almost always more cumbersome or limited than the new digital tools. Unlike the telephone, radio or television, the Internet is a many-to-many communication medium.

The Internet is a network of networks. It is a global set of connections of computers that enables the exchange of data, news and opinion. Aside from being a communications medium, the Internet has become a platform for new ways of doing business, a better way for governments to deliver public services and an enabler of lifelong learning. The Internet has become the fastest growing mass medium.

\section{Some of the consequences of the digital and ICT revolutions}

The progressive digitization of mass media and telecommunications content begins to blur earlier distinctions between the communication of information and its processing, as well as between people and machines. Digitization makes communications from persons to machines, between machines, and even from machines to persons as easy as it is between persons. Also blurred are the distinctions among information types: numbers, words, pictures, and sounds, and eventually even sensations, all might be stored, processed, and communicated in the same digital format.

On a societal level, the digital and ICT revolutions make possible better and cheaper access to knowledge and information. This speeds up transactions and processes and reduces their cost, which in turn benefit citizens and consumers.

The ability of ICTs to traverse time and distance allows human beings to interact with each other in new ways. 
Technological revolutions are all characterized by their pervasiveness, that is by their penetration of all domains of human activity, not as an exogenous source of impact, but as the fabric in which such activity is integrated.

New technologies threaten existing power and economic relationships, and those that benefit from these old relationships put up barriers to the spread of the new technologies. Moreover, laws can deter (or encourage) the spread of new technologies. For example, the lack of legal recognition for digital contracts and digital signatures is holding back electronic commerce.

The establishment of property rights is one of the most crucial events along the technological frontier. It allows the market to unfold in a predictable way, and gives pioneers a hefty dose of ownership and security. Most important, perhaps, the creation of property rights also marks the difference between pioneers and pirates, between those whose claim on the new technology is legitimate and those whose claim is not.

\section{The main features of the information economy}

The information economy is global. A historically new reality, the global economy has the capacity to work as a unit in real time on a planetary scale. Corporations and firms now have a worldwide base for skilled labor to tap. Capital flows freely between countries, and countries can utilize this capital in real time.

However, some critics claim that a true global economy has yet to be achieved. Multinational corporations still maintain their assets and strategic command centers in their home nations, and capital is still limited by banking and finance laws.

Even if globalization has not yet been fully realized, it will only be a matter of time before this happens. Globalization will be affected by government regulations and policies, which will affect international boundaries and the structure of the global economy.

A second characteristic of the information economy is that it is highly productive. Productivity growth in the new economy sectors has made a significant contribution to economywide productivity growth. Some critics argue that there is no relationship between profitability and investment in ICT.

A third characteristic of the information economy is the change in the manner of obtaining profits. Now profits come from speed of innovation and the ability to attract and keep customers. Where before the winners were big corporations, now the winners are small, highly flexible groups that devise great ideas, develop trustworthy branding for themselves and their products, and market these effectively. The winning competitors are those who are first at providing lower prices and higher value through intermediaries of trustworthy brands. But the winning is temporary, and the race is never over. Those in the lead cannot stop innovating lest they fall behind the competition.

\section{Information economy, knowledge economy, digital economy, or the network economy}

The terms information economy, knowledge economy, digital economy, or the network economy are used interchangeably. Various observers describe today's global economy as one in transition to a knowledge economy, as an extension of an information society. The transition requires that the rules and practices that determined success in the industrial economy need rewriting in an interconnected, globalized economy where knowledge resources such as know-how and expertise are as critical as other economic resources. According to analysts of the knowledge economy, these rules need to be rewritten at the levels of firms and industries in terms of knowledge management and at the level of public policy as knowledge policy or knowledge-related policy.

The initial foundation for the knowledge economy was first introduced in 1966 in the book The Effective Executive by Peter Drucker.The knowledge economy is a networked economy. The concept stresses the important role of links among individuals, groups and corporations in the new 
economy. It has been argued that networks have always been an ideal organizing tool due to their inherent flexibility and adaptability.

A digital economy is an economy that is based on electronic goods and services produced by an electronic business and traded through electronic commerce. That is, a business with electronic production and management processes and that interacts with its partners and customers and conducts transactions through Internet and $\mathrm{Web}$ technologies.

\section{Electronic business}

Electronic Business, commonly referred to as eBusiness or e-Business, may be defined as the utilisation of information and communication technologies (ICT) in support of all the activities of business. Commerce constitutes the exchange of products and services between businesses, groups and individuals and hence can be seen as one of the essential activities of any business. Hence, electronic commerce or eCommerce focuses on the use of ICT to enable the external activities and relationships of the business with individuals, groups and other businesses.

In practice, e-business is more than just e-commerce. While e-business refers to more strategic focus with an emphasis on the functions that occur using electronic capabilities, $e$ commerce is a subset of an overall e-business strategy. E-commerce seeks to add revenue streams using the World Wide Web or the Internet to build and enhance relationships with clients and partners and to improve efficiency. Often, e-commerce involves the application of knowledge management systems. E-business involves business processes spanning the entire value chain: electronic purchasing and supply chain management, processing orders electronically, handling customer service, and cooperating with business partners. Special technical standards for $e$-business facilitate the exchange of data between companies. E-business software solutions allow the integration of business processes. E-business can be conducted using the Web, the Internet, intranets, extranets, or some combination of these.

The software used for computers merely reorganizes traditional work, which had been based on experience. This is done through the application of knowledge, in particular systematic, logical analysis. Setting up an IT structure is not enough. To maintain leadership in the new economy, the social position of knowledge professionals and the social acceptance of their values should be guaranteed.

Technological development, from better transportation and carrier services to the telephone and mass media, has created a smaller, more integrated world. Now, the ICT revolution is making the world even smaller and more integrated. Communications, trade and employment, personal and political transactions are now occurring on a global scale, in real time, ignoring boundaries between states.

The ICT revolution has transformed not only how (and where) goods are produced but also how commodities are exchanged. E-commerce is buying and selling over the Internet or any transaction concluded through an information network involving the transfer of ownership or rights to use goods or services. More precisely, it includes all business transactions that use electronic communications and digital information processing technology to create, transform and redefine relationships for value creation between organizations, and between organizations and individuals. The different types of e-commerce are: business-to-business (B2B); business-to-consumer (B2C); business-to-government (B2G); consumer-to-consumer (C2C); and mobile commerce (mcommerce).

\section{Collaborative Working Environment}

A Collaborative Working Environment (CWE) supports people in their individual and cooperative work. Research in CWE involves organisational, technical, and social issues. An 
emerging category of computer software, collaboration platforms are unified electronic platforms that support synchronous and asynchronous communication through a variety of devices and channels.

Collaboration platforms offer a set of software components and software services that enable individuals to find each other and the information they need and to be able to communicate and work together to achieve common business goals. The core elements of a collaboration platform are messaging (email, calendaring and scheduling, and contacts), team collaboration (file synchronization, ideas and notes, task management, full-text search), and real-time collaboration and communication (e.g., presence, instant messaging, Web conferencing, application / desktop sharing, voice, audio and video conferencing), and Social Computing tools (e.g., blog, tagging, shared bookmarks).Actually, the Collaboration platforms could be proprietary or open source or free software, and tend to be used in a wider information and communication environments, representing the collaboration platform one module or package more to be integrate in a bigger platform.

\section{Content management systems}

A content management system (CMS) is a computer application used to create, edit, manage, and publish content in a consistently organized fashion. CMSs are frequently used for storing, controlling, versioning, and publishing industry-specific documentation such as news articles, operators' manuals, technical manuals, sales guides, and marketing brochures. The content managed may include computer files, image media, audio files, video files, electronic documents, and Web content.

\section{Standardization}

OASIS (Organization for the Advancement of Structured Information Standards) is a notfor-profit consortium that drives the development, convergence and adoption of open standards for the global information society. The consortium produces more Web services standards than any other organization along with standards for security, e-business, and standardization efforts in the public sector and for application-specific markets. Founded in 1993, OASIS has more than 5,000 participants representing over 600 organizations and individual members in 100 countries.

The Consortium hosts two of the most widely respected information portals on XML and Web services standards, Cover Pages and XML.org. OASIS was founded in 1993 under the name SGML Open as a consortium of vendors and users devoted to developing guidelines for interoperability among products that support the Standard Generalized Markup Language (SGML). OASIS changed its name in 1998 to reflect an expanded scope of technical work, including the Extensible Markup Language (XML) and other related standards.

Electronic Business using eXtensible Markup Language, commonly known as e-business $X M L$, or $e b X M L$ as it is typically referred to as, is a family of XML based standards sponsored by OASIS and UN/CEFACT whose mission is to provide an open, XML-based infrastructure that enables the global use of electronic business information in an interoperable, secure, and consistent manner by all trading partners.

The ebXML architecture is a unique set of concepts; part theoretical and part implemented in the existing ebXML standards work.

The International Organization for Standardization (ISO) has approved the following five ebXML specifications as the ISO 15000 standard, under the general title, Electronic business eXtensible markup language:

ISO 15000-1: ebXML Collaborative Partner Profile Agreement

ISO 15000-2: ebXML Messaging Service Specification 
ISO 15000-3: ebXML Registry Information Model

ISO 15000-4: ebXML Registry Services Specification

ISO 15000-5: ebXML Core Components Technical Specification, Version 2.01.

\section{Electronic Data Interchange}

Electronic Data Interchange (EDI) refers to the structured transmission of data between organizations by electronic means. The National Institute of Standards and Technology (NIST) defines Electronic Data Interchange as the computer-to-computer interchange of strictly formatted messages that represent documents other than monetary instruments. EDI implies a sequence of messages between two parties, either of whom may serve as originator or recipient. The formatted data representing the documents may be transmitted from originator to recipient via telecommunications or physically transported on electronic storage media.

Even in this era of technologies such as XML web services, the Internet and the World Wide $W e b$, EDI is still the data format used by the vast majority of electronic commerce transactions in the world. The EDI standards were designed to be independent of communication and software technologies. EDI can be transmitted using any methodology agreed to by the sender and recipient. This includes a variety of technologies, including modem (asynchronous, and bisynchronous), FTP, Email, HTTP, AS1, AS2, etc. It is important to differentiate between the EDI documents and the methods for transmitting them. When they compared the bisynchronous protocol $2400 \mathrm{bit} / \mathrm{s}$ modems, CLEO devices, and value-added networks used to transmit EDI documents to transmitting via the Internet, some people equated the non-Internet technologies with EDI and predicted erroneously that EDI itself would be replaced along with the non-Internet technologies. These noninternet transmission methods are being replaced by Internet Protocols such as FTP, telnet, and Email, but the EDI documents themselves still remain.

There are four major sets of EDI standards:

- The UN-recommended UN/EDIFACT is the only international standard and is predominant outside of North America.

- The US standard ANSI ASC X12 (X12) is predominant in North America.

- The TRADACOMS standard developed by the ANA (Article Numbering Association) is predominant in the UK retail industry.

- The ODETTE standard used within the European automotive industry

\section{Top 10 technologies to watch over the next three years}

At the recent Gartner Symposium 2008 ITxpo, Gartner analysts presented their insights into the top 10 technologies and trends to rule the world in 2009.With emphasis on virtualization, organizations should also pay close attention to cloud computing, green IT, Business Intelligence (BI) and social software - among other strategic trends. These technologies impact the organization's long-term plans, programs and initiatives. They may be strategic because they have matured to broad market use, or because they enable strategic advantage from early adoption.

Gartner definition: a strategic technology is one with the potential for significant impact on the enterprise in the next three years. Factors that denote significant impact include a high potential for disruption to IT or the business, the need for a major dollar investment, or the risk of being late to adopt. Companies should factor these technologies into their strategic planning process by asking key questions and making deliberate decisions about them during the next two years. Sometimes the decision will be to do nothing with a particular technology. In other cases it will be to continue investing in the technology at the current rate. In still other cases the decision may be to test/pilot or more aggressively adopt/deploy the technology. 
Gartner analysts gave a crowd of IT leaders at the Gartner Symposium ITxpo 2008 a list of the top 10 technologies that will provide important strategic advantages to IT over the next three years. They encouraged the leaders to keep these technologies in mind as they formulate budgets and long-term plans. Companies should look at these 10 opportunities and evaluate where these technologies can add value to their business services and solutions, as well as develop a process for detecting and evaluating the business value of new technologies as they enter the market."

The list in the presentation "Top 10 Strategic Technology Areas for 2009" at the Orlando event contains:

1. Virtualization. Virtualization in storage and client devices is also moving rapidly. In addition, such virtualization trends as data deduplication can significantly decrease the cost of storage devices and media to hold information. Gartner notes that, despite ambitious deployment plans from many organizations, deployments of hosted virtual desktop capabilities will be adopted by fewer than $40 \%$ of target users by 2010 .In the current economic slump, organizations can get more for implementing virtualization software rather than buying new servers. There are plenty of virtualization products on the market right now to help tight IT budgets

2. Cloud Computing. With players like Amazon Web Services, Google Apps, IBM, HP and many others already in the cloud, cloud computing is another hot topic. As per Gartner, the key characteristics of cloud computing are:

- SaaS capabilities

- Delivery of services in a highly scalable and elastic fashion

- Usage of Internet technologies and techniques to develop and deliver the services

- Designing for delivery to external customers

- Some of the potential benefits of cloud computing include cost savings and the built-in elasticity. These features allow for lower barriers to entry and quick scalability and growth.

3. Beyond Blade Servers Just like it was predicted earlier this year, green IT is much hyped about, and servers will continue to evolve in 2009 beyond the blade server stage that exists today. This evolution will simplify the provisioning of capacity to meet growing needs. It will also make it easier on the inventory of systems, eliminating the need to track and purchase various sizes and configurations. The result will be higher utilization because of lessened "waste" of resources that are in the wrong configuration, for example.

4. Green IT. Going hand in hand with growing beyond blade servers, shifting to more efficient products can allow for a greener energy footprint. Multiple regulations are out there designed to govern companies in building data centers due to their impact on power grids and carbon emissions.

5. Web-Oriented Architectures. With the continuing emergence of Web-centric technologies and standards, Gartner expects that continued evolution of the Web-centric approach will enable its use "in an ever-broadening set of enterprise solutions during the next five years."

6. Enterprise Mashups. Much in agreement with Forrester Research, Gartner believes that in 2009 enterprises may be taking mashups from Web 2.0 to Enterprise 2.0 levels "to augment their models for delivering and managing applications."

Through 2010, the enterprise mashups should experience significant development in a search for potential benefit they may offer to enterprises.

7. Specialized Systems. Heterogeneous systems seem to be an emerging trend in highperformance computing to address the requirements of the most demanding workloads. Gartner predicts that this approach will eventually reach the general-purpose computing market. Heterogeneous systems are viewed as specialized systems with the same single-purpose imitations of appliances, but the heterogeneous system is a server system, into which the owner installs software to accomplish its function.

8. Social Software and Social Networking. Social software - in all its shapes and forms of social networking, social collaboration, social media and social validation — is something 
organizations should consider along with mashups. Gartner thinks it's better to adopt a social platform sooner, rather than later, because the greatest risk lies in failure to engage by coming too late to the party.

9. Unified Communications. According to Gartner, during the next five years the number of different communications vendors will be reduced by at least 50\% due to the increased capability of application servers. Hence, there could be a massive consolidation in the communications industry. Organizations must build careful, detailed plans for all their communications functions' replacement and convergence.

10. Business Intelligence (BI). BI has the potential to positively impact a company's business performance, dramatically improving its ability to accomplish its mission by making smarter decisions at every level of the business, says Gartner.

$B I$ is particularly strategic due to its relation towards business managers and knowledge workers - the main organizational thinkers and decision-makers. Providing them with appropriate BI tools will only make their jobs so much more effective and easier.

Strategic technologies affect, run, grow and transform the business initiatives of an organization. Companies should look at these 10 opportunities and evaluate where these technologies can add value to their business services and solutions, as well as develop a process for detecting and evaluating the business value of new technologies as they enter the market.

\section{References:}

1. Carl Claunch and Dave Cearley, Top 10 Strategic Technology Areas for 2009, Gartner Symposium/2008 ITxpo, Orlando, 2008. Ohmae, Kenichi, The invisible continent: four strategic imperatives of the new economy, New York, Harper Business, 2000Sam Lubbe, Documentation Standards for E-commerce Organizations, ISACA, Information Systems Control Journal, Volume 5, ISSN (1526-7407), 2003,

2. Prakash, Aseem \& Jeffrey A. Hart, Globalization and governance, London: Routledge, eds. 1999. Shapiro, Carl \& Hal Varian, Information Rules: A Strategic Guide to the Networked Economy, Boston, Harvard Business School Press, 1999.

3. Progress in making e-services accessible to all, National Audit Office UK, $\mathrm{http}: / / \mathrm{www} . n a o . g o v . u k / \mathrm{pn} / 02-03 / 0203428 . \mathrm{htm}$ (last seen 24.4.2008)

4. Sam Lubbe, Documentation Standards for E-commerce Organisations, ISACA, Information Systems Control Journal, Volume 5, 2003, ISSN (1526-7407), p.24.

5. Minimum technical standards for government websites, World Wide Consortium (W3C), http://www.w3c.org

6. Web Application Security, Ken Stasiak, ISACA, Information Systems Control Journal, Volume 6, 2002, ISSN (1526-7407), p. 44. 